\title{
The Review of Empowerment Leadership
}

\author{
Yingying Liu \\ School of Management, Jinan University, Guangzhou, China \\ Email: 1329376322@qq.com
}

Received 12 October 2015; accepted 26 October 2015; published 29 October 2015

Copyright (C) 2015 by author and Scientific Research Publishing Inc.

This work is licensed under the Creative Commons Attribution International License (CC BY). http://creativecommons.org/licenses/by/4.0/

(c) (i) Open Access

\begin{abstract}
First, the paper starts with the meaning of power and empowerment and discusses the concept of empowering leadership. It summarizes the constructs and measuring instruments of empowering leadership by literature analysis. Second, on the basis of empirical researches, it analyzes the antecedents and effectiveness as well as intervening factors. Finally, it points out the limitations of current researches and some prospects for the future research.
\end{abstract}

\section{Keywords}

Leadership, Empowering Leadership, Antecedents, Effectiveness

\section{Introduction}

Leadership is a hotspot in the field of management science. The earliest research that uses scientific method can be traced back to leadership trait theory in the early 20th century [1]. And then, more researches on leadership theory are sprung out, including four-graph theory of Ohio State University, leadership system model theory of University of Michigan, situational leadership theory, the path goal theory, two factor theory of transformational leadership and transactional leadership.

In recent years, enterprises are facing profound technology and business revolution. These changes bring flat and centralized organization design, flexibility, customer orientation, the improvement of quality and efficiency. In addition, the nature of work has changed a lot. It becomes more complex and demands more cognition. "Intellectual employee" becomes the core of the quickly increasing labor. Under the background of such a change, the empowerment leadership is born as a special kind of leader.

The concept of empowerment leadership was proposed in 1990s. Manz originally called empowerment leadership as "super leadership" [2]. Pearce extended leadership theory and proposed four factor theory consisted of transformational leadership, transactional leadership, instrumental leadership and empowerment leadership by exploring factor analysis [3]. And he confirmed its validity through confirmatory factor analysis with the third sample. So empowerment leadership could be isolated as an independent type of leadership. Difference from 
traditional leadership style, empowerment leadership emphasized the process of subodinate's self-influence instead of level control.

\section{The Meaning of Empowerment Leadership}

\subsection{Social Relationship Perspective}

According to social exchange theory, power is a concept that can reflect social concept. It represents the interdependent social function and the asymmetric control of resources and results in the context of a particular situation and social relations [4]. This definition implies two characteristics of power: controlling others and be independent of others in order to achieve their goals. Power works as a control mechanism. The one who owns power can drive others to help them achieve their goals. In another word, power is the ability not influenced by others. A person will be subject to others without power and he will be relatively free with power. Power source can be the individual's ability to provide valuable resources to the organization. It can also be his position in the organization structure, professional skills and opportunity to access to specific knowledge or information, etc.

From this perspective, empowerment is a kind of resource allocation strategy that can reduce the dependence on high power. The empowerment leadership behavior can be defined as a series of management practices, including decentralization, participation, information sharing and training [5] [6].

\subsection{Psychological Motivation Perspective}

In the psychological literature, power and control are used to describe the state of belief individual's internal motivation or expectation. For example, the individual is considered to have the need for power [6]. In another word, he has the internal need to influence and control others. Power and control have drawn many psychologists' attention. Their studies include internal/external control, acquisition, the main/secondary control. Individual's power needs will be met when they perceive that they have power or they believe they can adequately handle life events, situations or people attached to them. On the other hand, when the individual feels that power is very low, or they think they cannot handle the physical or social requirements that are raised by the environment, their power needs will not be met. Under the perspective of this research, power is related to an inner selfdetermining demand or a belief in individual self-efficacy [7].

Empowerment leadership behaviors from this perspective include any management decision or technology that can improve employee's inner level of motivation by enhancing his self-determining demand or self-efficiency [8] [9]. Thomas believed that empowerment was an improvement on the level of intrinsic motivation, and proposed the concept of "psychological empowerment" [10]. Spreitzer explained employees' perception of power as the four aspects of employee's perception of work meaning, self-efficacy, autonomy and influence [11].

\section{Construction and Measurement}

From these two theoretical perspectives, scholars have made different discussions on the structure and measurement method of the empowerment leadership. From the perspective of psychological empowerment, Thomas proposed a cognitive model composed of sense of meaning, sense of competency, sense of autonomy and impact [10]. On the base of this model, Spreitzer developed a multidimensional scale of psychological empowerment [11]. And he confirmed the validity of this four-dimension scale through the two-order confirmatory factor analysis. Using empirical research method, Li Chaoping et al. verified the applicability of Spreitzer's psychological empowerment scale on the background of Chinese culture through twice questionnaire surveys on 23 companies [12]. And he examined empowerment's impact on employee attitude with this scale. Ahearne divided the empowerment leadership behavior into four dimensions [8], and developed an empowerment leadership scale on the basis of qualitative study of Conger [9] and empirical study of Hui and Thomas [13]. The scale has the high reliability with the internal consistency coefficient of 0.88 .

From the perspective of management practice, Arnold explored the structure of empowerment leadership through a qualitative study and two quantitative studies [14]. Firstly, he commenced on a comprehensive interview of 195 people from three organizations, including external leaders and internal members and getting the preliminary dimension of empowerment leadership behavior. Then he abstracted five factors of leading by ex- 
ample, participatory decision-making, counseling, information sharing and caring through questionnaire surveys, which was confirmed to have high validity by further cross validation. The empowerment leadership behavior questionnaire ELBQ established by Konczak contained 6 dimensions and 17 items [15]. The dimensions include decentralization of authority, emphasis on responsibility, encouraging independent decision-making, sharing information, cultivating skills and encouraging innovation. The examination result showed that consistency coefficients $(0.82-0.90)$ of all projects reach the standard. Wang Hui studied the dimension and measurement of empowerment behavior in the context of Chinese enterprises using empirical research methods [16]. The content of empowerment leadership was divided into six dimensions: personal development support, process control, power appointment, results and target control, participative decision-making and work instruction. In this study, Wang Hui developed an empowerment leadership scale consisted of 24 items. The structure validity of the scale was confirmed by a further confirmatory factor analysis, and the internal consistency analysis showed that the scale had a good reliability.

In summary, the research on the structure and measurement of the empowerment leadership in foreign countries is very rich. And the measurement is more in the form of questionnaire, which reflects leader's empowerment behavior by subject report. Because of the huge difference between Chinese and Western culture, is the foreign scale suitable for the study of the organizational behavior in the context of Chinese culture. In recent years, although some domestic scholars have seen this difference and begun to explore the structure of the empowerment leadership under the situation of China, but the research number is relatively small. Nowadays the positive studies in our country mostly use the six-dimension scale developed by Pearce and Sims in 2000 which included encouraging self-reward, encouraging teamwork, participative goal setting, encouraging independent action, encouraging opportunity thinking and encouraging self-development. So the future study should dedicate to make up for this shortage. To explore the most effective empowerment leadership behavior in different industries under Chinese culture background and develop correspondent scale, laying foundation for future study.

\section{The Antecedents of Empowerment Leadership}

The previous studies on the antecedents of empowerment leadership can be classified to four types: individual level factors (sex, personality, control desire), leader-subordinate relationship factors (trust, leader-member exchange), organization level factors (organization system control) and culture factors (power distance, uncertainty avoidance).

It was found that trust was the basis of empowerment leadership behavior [17]. Hakimi thought that leader's trust degree in subordinate's performance and integrity can positively predict empowerment leadership behavior which is moderated by responsibility of the big five personality [5]. Wei Huimin found that leader's cognitive trust and emotional trust in the subordinate are both helpful to increase the empowerment leadership behavior, in which cognitive trust has the greatest influence on the decision-making participation dimension of empowerment behavior and emotional trust has the greatest influence on information sharing dimension and coach dimension of empowerment behavior [18]. This study also found the moderation role of system control and leader's power distance between trust and empowerment leadership behavior.

Spreitzer considered that if a leader chooses to empower or not, to a large extent, depends on his cognition in the risk of empowerment and the willingness to take risks [11]. Yang Ying found that task performance, power status, organizational interests risk considerations will negatively affect the leader's empowerment behavior, and this negative relationship is subject to leadership-member exchange (LMX) and organizational centralization [19].

Offerman found that uncertainty avoidance is positively related to leadership control through cross cultural study, but negatively related to empowerment and kindness [20]. The study launched by Liu Wenxing from the perspective of value and work characteristics found that uncertainty avoidance will hinder leadership empowerment behavior and workload will promote leadership empowerment behavior. It was also found that leader's position level and control willingness of external things play a regulatory role [21].

There are studies that have found the effects of gender on empowerment. Rosener found that male managers were more likely to have transactional leadership compared with female managers, exchanging reward and punishment for performance and using power from the position and authority [22]. Robins found that female manager is more likely to show democratic and participatory leadership and employee oriented leadership. The meta- 
analysis results given by Eagly shown that female managers exhibited more transformational leadership behaviors and male managers showed more transactional leadership behaviors [23]. However, there are some studies, on the contrary, found that gender had no significant effect on the leadership empowerment behavior, such as Slaughter's study for 141 subordinates and 33 IT project supervisor shown that gender had no obvious effect on the leadership style [24].

\section{The Effectiveness of Empowerment Leadership}

On the basis of synthesizing previous study, Raub explored the effectiveness of the empwoerment leadership on individual level [25]. The research explored a series of behavioral outcome variables of different levels from the perspective of empowerment leadership practice and psychological empowerment. The research objects were frontline service staff and their supervisors from Middle East and Asia Pacific division of a multinational chain hotel. The research model is shown in Figure 1, which included the responsibility oriented in-role behavior and the interpersonal cooperation oriented external role behavior of affinity and the challenging status quo oriented challenging external role behavior. The study confirmed the effectiveness of the empowerment leadership on employee's behavioral outcomes on three levels and shown that psychological empowerment was an important intermediate variable between the empowerment leadership and challenging external role behavior. This finding of the effectiveness of empowerment leadership on individual level had been confirmed by relevant researches. Gao studied challenging external role behavior, voice behavior, of employees from the telecommunication industry and found employee's trust in supervisor and empowerment leadership behavior were important factors to promote employee voice [26]. Chen examined the mechanism of the impact of empowerment leadership on team members, and the research found that empowerment leadership positively affected cooperation behavior and innovative behavior of the team through psychological empowerment and affective commitment [27].

Kirkman launched empirical research on empowerment leadership from the perspective of group level which was shown in Figure 2 [28]. The sample was selected from four companies in the United States, two of which were large firms ranking among Fortune 50 and two other small companies. The results shown that empower-

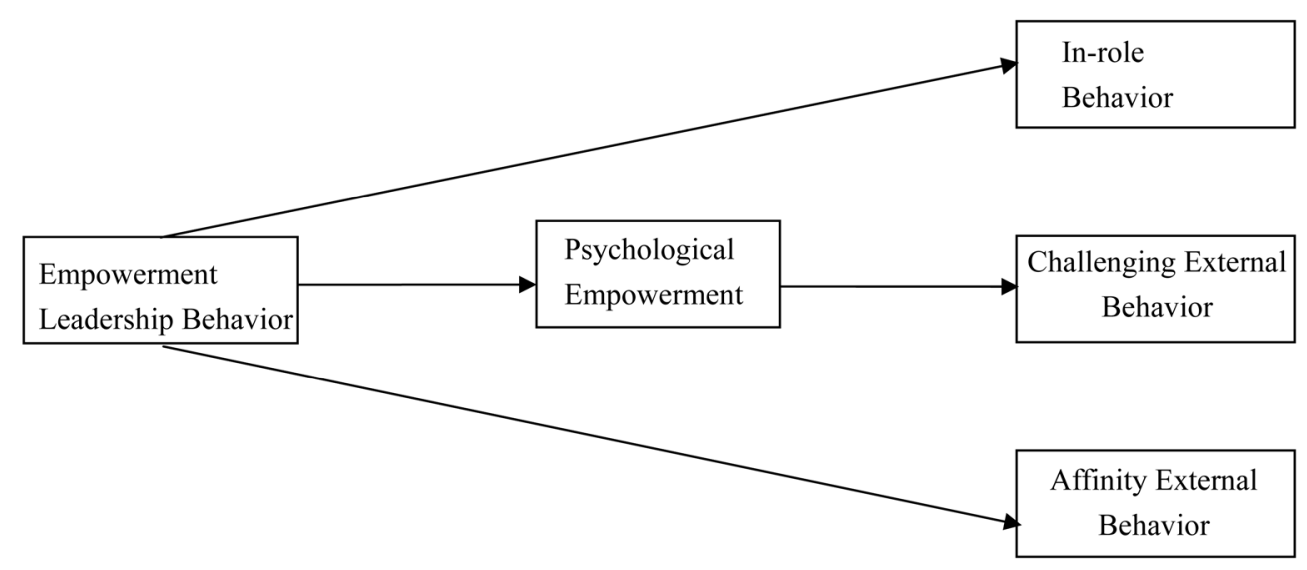

Figure 1. Empowerment leadership effectiveness model of Raub [25].

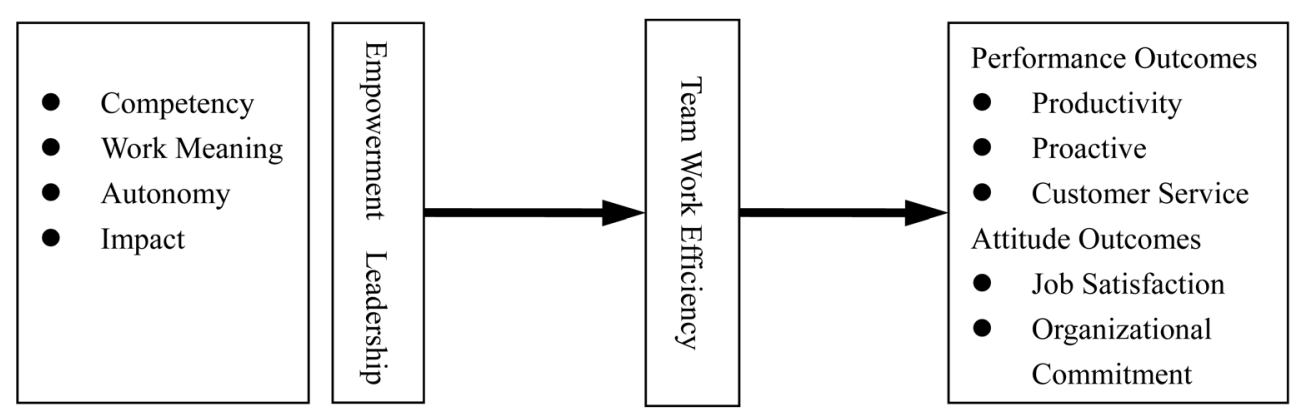

Figure 2. Empowerment leadership effectiveness model of Kirkmanet [28]. 
ment leadership on group level which included four dimensions of potency, meaningfulness, autonomy and impact was more likely to improve organization performance in comparison with the traditional leadership. And the improvement was mainly reflected in employee performance results like team productivity, proactive and customer service quality and employee attitude like job satisfaction and organizational commitment.

Humborstad confirmed that empowerment leadership was important to job performance [29]. Wellins found that the empowered team was more proactive, seeking continuous improvement on the quality of work, continuous optimization of work process, searching for creative solutions [30]. Guzzo considered the team with higher sense of competency would provide better service for both internal and external customers [31]. Gorn considered employee's job satisfaction would be higher when the work was more meaningful [32]. Cordery found the empowered team had higher organizational commitment level compared with the traditional team in the same company [33]. Through analysis of the differences between teams, Kai further confirmed empowerment leadership could predict employee's job satisfaction and organizational commitment level [34].

Kirkman believed that the future research should focus on the combination of individual level and group level [28]. In addition, it is necessary to carry out the cross-industry research to improve the generalization and popularization of the conclusions.

In addition to researches of individual level and group level, a few researchers have examined the effectiveness of the empowerment leadership on organizational level like Figure 3. Birdi analyzed the performance data of 308 British manufacturing firms which was provided by the UK credit information institution. The data covered financial performance from 1980 to 2003 of the entire UK business community. Three longitudinal studies by telephone interview and questionnaire survey established that the enterprise performance benefited from its empowerment practice. However, the study did not distinguish between middle managers and senior managers and further examined the effect of penetration degree of enterprise's empowerment practice on the organizational effectiveness. Carmeli made up for this deficiency. He found that CEO's empowerment leadership style could enhance the effectiveness of the executive team (TMT), thereby improving corporate performance. However, in addition to corporate performance on organizational level, what else aspects of the enterprise could empowerment leadership have an impact on? There are few studies on this problem. So studies on the effectiveness of empowerment leadership on organization level need to be further improved.

\section{Review and Prospect}

In the empowerment leadership team, employees are granted more autonomy, self-leadership and control of the work environment. On the other hand, managers are required to provide support, encouraging self management and increasing empowerment. In addition, managers should also set an example, provide information and resources, encourage self-reinforcement and build trust. An authorized organization can better cope with the change of bussiness environment brought by increasingly fierce global competition, can meet customer requirements for higher quality of products and adapt to the transformation from manufacturing enterprises to service-oriented enterprises. Therefore, managers should pay attention to the training of empowerment leadership behaviors like providing support and encouragement, decentralizing and participative decision-making, leading the team by assuming new role and responsibility.

Although the research of the authorized leadership is getting more and more attention in recent years, there are some problems and shortcomings in the existing research. First of all, the empowerment leadership theory

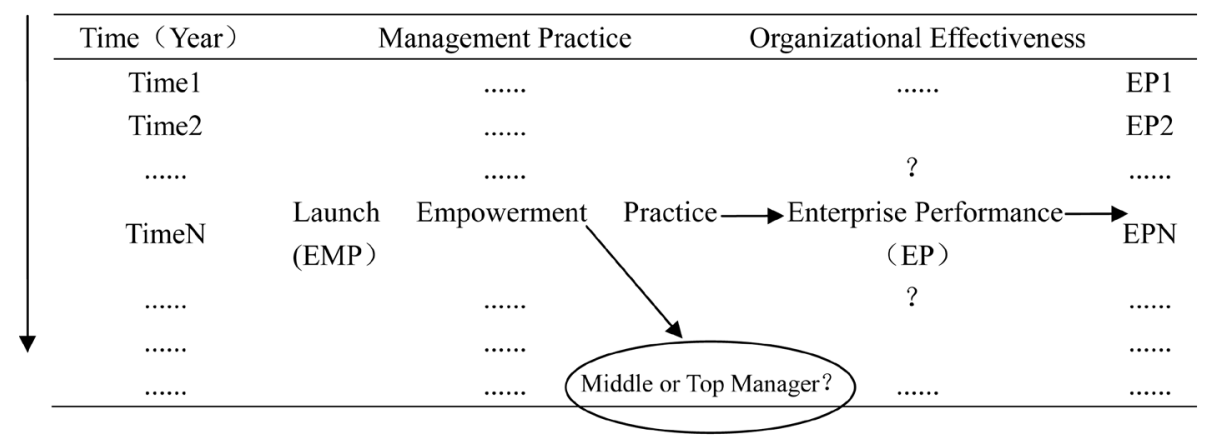

Figure 3. Empowerment leadership effectiveness model of Birdi. 
originates from the Western cultural background. Western scholars have carried out a lot of researches on the structure of empowerment leadership from different perspectives, and have made abundant achievements with empowerment leadership scales for different situation developed. But there are few studies in this field in China. A relative lack of research on the structure and measurement of empowerment leadership under localization background hinders the development of empowerment leadership theory in China. The existing research mostly adopts the single measurement method of questionnaire which is easy to produce error. Empowerment leadership should be measured from different perspectives by combining with multiplex methods as case study and indepth interview to ensure the accuracy. In addition, future research should attach more weight to the test of validity of empowerment leadership scale. Secondly, the practical significance of empowerment leadership has been confirmed by a large number of studies. But there is little research on how to build authorized organization in order to achieve efficient management. Therefore, the study on antecedents of empowering leadership needs to be improved. In addition, the future research should dedicate to exibit a full model from the overall perspective by integrating studies on antecedents and effectiveness of empowerment leadership. Throughout previous studies, it is found that the study on outcome variables of empowerment leadership focuses on individual level and group level. Under the influence of economic globalization, more and more enterprises are seeking strategic cooperation to enhance their competitiveness. As a result, they depend more on external forces of upstream and downstream in the industry chain. So it is necessary to give attention to the impact of empowerment leadership on stakeholders in the industrial chain from organizational level.

Finally, western culture that originated from the commodity economy is characterized by strong individualism and small power differential. But Chinese culture that originated in the natural economy has a long history of centralized system which means a big power differential. The future study can focus on the difference of empowerment leadership under different cultural backgrounds from the perspective of cross culture. The test of the effect of empowerment leadership mostly adopts cross-sectional study method in the past. But empowerment leadership behavior tends to be fluctuant over time to adapt to the change of organizational environment. Therefore, future research should pay attention to the application of longitudinal research method and make the research results more according with the reality of enterprise.

\section{References}

[1] Li, Y. and Wei, F. (2010) Evolution of Leadership Theory and Frontier Progress. Journal of Management, 4, 517-524.

[2] Manz, C.C. and Sims, H.P. (1990) Super Leadership. Berkeley Books, New York.

[3] Pearce, C.L., et al. (2003) Transactors, Transformers and beyond: A Multi-Method Development of a Theoretical Typology of Leadership. Journal of Management Development, 22, 273-307. http://dx.doi.org/10.1108/02621710310467587

[4] Magee, J.C., et al. (2008) Power and the Objectification of Social Targets. Journal of Personality \& Social Psychology, 95, 111-127. http://dx.doi.org/10.1037/0022-3514.95.1.111

[5] Hakimi, N., et al. (2010) Leader Empowering Behavior: The Leader’s Perspective. British Journal of Management, 21, 701-716. http://dx.doi.org/10.1111/j.1467-8551.2010.00703.x

[6] McClelland, D.C. (1975) Power: The Inner Experience. Vol. 95, Irvington Publishers, New York, 427-429.

[7] Bandura, A. and Gervone, D. (1986) Differential Engagement of Self-Reactive Influences in Cognitive Motivation. Organizational Behavior \& Human Decision Processes, 38, 92-113. http://dx.doi.org/10.1016/0749-5978(86)90028-2

[8] Ahearne, J.M., et al. (2005) To Empower or Not to Empower Your Sales Force? An Empirical Examination of Influence of Leadership Empowerment Behavior on Customer Satisfaction and Performance. Journal of Applied Psychology, 90, 945-955. http://dx.doi.org/10.1037/0021-9010.90.5.945

[9] Conger, J.A. and Kanungo, R.N. (1988) The Empowerment Process: Integrating Theory and Practice. Academy of Management Review, 13, 471-482.

[10] Thomas, K.W. and Velthouse, B.A. (1990) Cognitive Elements of Empowerment: An “Interpretive” Model of Intrsic Task Motivation. Academy of Management Review, 15, 666-681.

[11] Spreitzer, G.M. (1995) Psychological Empowerment in the Work-Place: Dimensions, Measurement, and Validation. Academy of Management Journal, 38, 1442-1465. http://dx.doi.org/10.2307/256865

[12] Thomas, K. and Tymon, W. (1994) Does Empowerment Always Work? Understanding the Role of Intrinsic Motivation and Personal Interpretation. Journal of Management Systems, 6, 1-13.

[13] Arnold, J.A., Arad, S., Rhoades, J.A. and Drasgow, F. (2000) The Empowering Leadership Questionnaire: The Con- 
struction and Validation of a New Scale for Measuring Leader Behaviors. Journal of Organizational Behavior, 21, 249-269. http://dx.doi.org/10.1002/(SICI)1099-1379(200005)21:3<249::AID-JOB10>3.0.CO;2-\#

[14] Konczak, L.J., Stelly, D.J. and Trusty, M.L. (2000) Defining and Measuring Empowering Leader Behaviors: Development of an Upward Feedback Instrument. Educational and Psychological Measurement, 60, 301-313. http://dx.doi.org/10.1177/00131640021970420

[15] Lee, M. and Koh, J. (2001) Is Empowerment Really a New Concept? International Journal of Human Resource Management, 12, 684-695. http://dx.doi.org/10.1080/713769649

[16] Wei, H.M. and Long, L.R. (2011) The Influence of Cognition and Emotional Trust, Sense of Power Distance and System Control on the Leadership Empowerment Behavior. Journal of Management Engineering, 5.

[17] Yang, Y., Long, L.R. and Zhou, L.F. (2010) Empowerment Risk Consideration and Empowerment Behavior: The Effect of Leadership-Member Exchange and Centralization Degree. Journal of Psychology, 42, 875-885.

[18] Offerman, L.R. and Hellmann, P.S. (1997) Culture’s Consequences for Leadership Behavior. Journal of Cross-Cultural Psychology, 28, 342-351. http://dx.doi.org/10.1177/0022022197283008

[19] Liu, W.X., Liao, J.Q. and Huang, S.H. (2010) Uncertainty Avoidance, Work Burden and Leadership Empowerment Behavior: The Moderate Effect of Controlling Desire and Management Hierarchy. Nankai Management Review, 15, 4-12.

[20] Rosener, J.B. (1990) Ways Women Lead. Harvard Business Review, 68, 119-125.

[21] Eagly, A.H., Johannesen-Schmidt, M.C. and van Engen, M.L. (2003) Transformational, Transactional, and LaissezFaire Leadership Styles: A Meta-Analysis Comparing Women and Men. Psychological Bulletin, 129, 569-591. http://dx.doi.org/10.1037/0033-2909.129.4.569

[22] Slaughter, B.B. (2012) The Relationship between Leader Gender and Empowering Behavior. Dissertation, Fielding Graduate University, Santa Barbara.

[23] Raub, S. and Robert, C. (2010) Differential Effects of Empowering Leadership on In-Role and Extra-Role Employee Behaviors: Exploring the Role of Psychological Empowerment and Power Values. Human Relations, 63, 1743-1770. http://dx.doi.org/10.1177/0018726710365092

[24] Gao, L., Janssen, O. and Shi, K. (2011) Leader Trust and Employee Voice: The Moderating Role of Empowering Leader Behaviors. The Leadership Quarterly, 22, 787-798. http://dx.doi.org/10.1016/j.leaqua.2011.05.015

[25] Chen, G., Sharma, P.N., Edinger, S.K., Shapiro, D.L. and Farh, J.-L. (2011) Motivation and Demotivating Forces in Teams: Cross-Level Influence of Empowering Leadership and Relationship Conflict. Journal of Applied Psychology, 96, 541-557. http://dx.doi.org/10.1037/a0021886

[26] Kirman, B.L. and Rosen, B. (1999) Beyond Self-Management: Antecedents and Consequences of Team Empowerment. Academy of Management Journal, 42, 58-74. http://dx.doi.org/10.2307/256874

[27] Humborstad, S.W., Nerstad, C.G.L. and Dysvik, A. (2014) Empowering Leadership, Employee Goal Orientations and Work Performance: A Competing Hypothesis Approach. Personnel Review, 43, 246-271. http://dx.doi.org/10.1108/PR-01-2012-0008

[28] Wellins, R.S., Byham, W. and Wilson, J. (1991) Empowered Teams: Creating Self-Directed Work Groups That Improve Quality, Productivity, and Participation. Jossey-Bass, San Francisco.

[29] Guzzo, R.A., et al. (1991) What Makes High-Performing Teams Effective? Unpublished Manuscript, University of Maryland, College Park.

[30] Gorn, G.J. and Kanungo, R.N. (1980) Job Involvement and Motivation: Are Intrinsically Motivated Managers More Job Involved? Organizational Behavior and Human Performance, 26, 265-277. http://dx.doi.org/10.1016/0030-5073(80)90059-8

[31] Cordery, J.L., Mueller, W.S. and Smith, L.M. (1991) Attitudinal and Behavioral Effects of Autonomous Group Working: A Longitudinal Field Study. The Academy of Management Journal, 34, 464-476. http://dx.doi.org/10.2307/256452

[32] Fong, K.H. and Snape, E. (2015) Empowering Leadership, Psychological Empowerment and Employee Outcomes: Testing a Multi-Level Mediating Model. British Journal of Management, 26, 126-138. http://dx.doi.org/10.1111/1467-8551.12048

[33] Birdi, K., Clegg, C., Patterson, M., Robinson, A., Stride, C.B., Wall, T.D. and Wood, S.J. (2008) The Impact of Human Resource and Operational Management Practices on Company Productivity: A Longitudinal Study. Personnel Psychology, 61, 467-501. http://dx.doi.org/10.1111/j.1744-6570.2008.00136.x

[34] Carmeli, A., Schaubroeck, J. and Tishler, A. (2011) How CEO Empowering Leadership Shapes Top Management Team Processes: Implications for Firm Performance. Leadership Quarterly, 22, 399-411. http://dx.doi.org/10.1016/j.leaqua.2011.02.013 